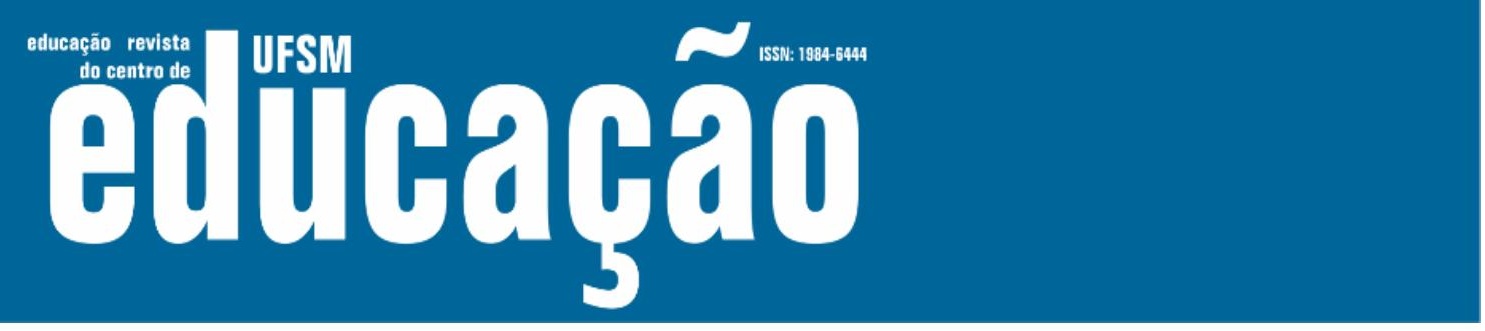

ISSN: 1984-6444 | http://dx.doi.org/10.5902/1984644461367

\title{
As percepções sobre os sujeitos da EJA e os materiais didáticos utilizados na mediação pedagógica na Educação de Jovens e Adultos
}

The perceptions about the subjects of the Education for Adults and Young People (EJA) and the teaching materials used in pedagogical mediation in the Education for youths and adults

Pollyana dos Santos

Professora doutora no Instituto Federal de Educação, Ciência e Tecnologia do Espírito Santo. Vitória, Espírito Santo, Brasil.

pollyanadossantos@yahoo.com.br - http://orcid.org/0000-0002-5239-1192

Maria Hermínia Lage Fernandes Laffin

Professora doutora na Universidade Federal de Santa Catarina, Florianópolis, Santa Catarina, Brasil. herminialaffin@gmail.com - https://orcid.org/0000-0002-4562-308X

Sonia Maria Chaves Haracemiv

Professora doutora na Universidade Federal do Paraná, Curitiba, Paraná, Brasil. sharacemiv@gmail.com - http://orcid.org/0000-0002-4827-8242

Recebido em 08 de outubro de 2020

Aprovado em 14 de dezembro de 2020

Publicado em 30 de março de 2021

\section{RESUMO}

O presente trabalho visa realizar uma articulação teórica sobre as percepções acerca dos sujeitos da EJA e a elaboração de materiais didáticos utilizados nas mediações pedagógicas nessa modalidade de ensino. A aproximação trazida neste artigo é um desdobramento de uma pesquisa do tipo estado do conhecimento que teve como objetivo identificar os principais fundamentos teórico-metodológicos presentes nas produções resultantes das pesquisas no campo da Educação de Jovens e Adultos no Brasil e que versam sobre os sujeitos estudantes. A partir desse levantamento, outros diálogos se tornaram possíveis e se estruturaram como questão para as reflexões aqui promovidas: como as percepções sobre os sujeitos estudantes, influenciam na escolha e/ou produção dos materiais didáticos utilizados nas mediações pedagógicas na EJA? A articulação teórica apresentada no artigo permitiu perceber que o entendimento sobre os sujeitos com os quais se trabalha na Educação de Jovens e Adultos e a compreensão de como jovens e adultos aprendem, influencia não apenas na escolha, como na produção e nas políticas de distribuição de materiais didáticos que corroboram com uma percepção sobre os sujeitos.

Palavras-chave: Sujeitos da EJA; Mediações Pedagógicas; Materiais Didáticos. 


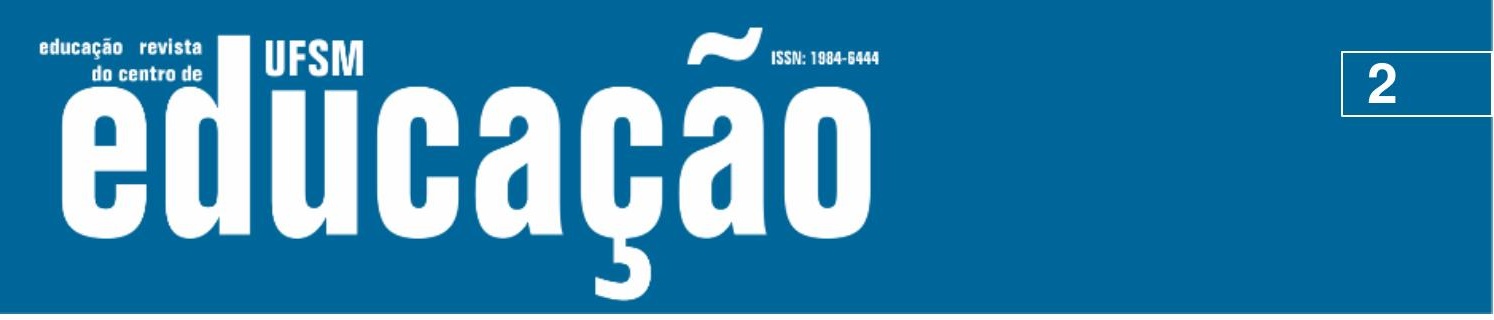

ISSN: 1984-6444 | http://dx.doi.org/10.5902/1984644461367

\section{ABSTRACT}

This article intends to make a theoretical articulation about the perceptions of the subjects of the EJA and the elaboration of didactic materials used in the pedagogical mediations in this modality of teaching. The approach brought in this paper is an unfolding of a state of knowledge research that aimed to identify the main theoretical and methodological foundations in the productions resulting from researching the field of Education for Youth and Adult in Brazil that deal with student subjects. From this survey, other dialogues have become possible and they organized themselves on the issue for the discussion developed here: how the perceptions about student subjects influence the choice and / or production of didactic materials used in pedagogical mediations in the EJA? The proposed theoretical articulation allowed us to realize that the understanding about the subjects with whom one works in the Education for Young and Adults and the comprehension of how young people and adults learn, influence not only the choice, but also the production and the policies of distribution of teaching materials that corroborate with a perception about the subjects.

Keywords: Subjects of the EJA; Pedagogical Mediations; Teaching materials.

\section{Introdução}

As motivações que deram início a este estudo são desdobramentos de uma pesquisa realizada sobre os fundamentos teórico-metodológicos que embasam as pesquisas no campo da Educação de Jovens e Adultos e que versam sobre os seus educandos.

Essa investigação se vincula a um projeto de pesquisa macro, intitulado Fundamentos e autores recorrentes do campo da Educação de Jovens e Adultos no Brasil: a construção de um glossário eletrônico ${ }^{1}$, e que se encontra em andamento. A pesquisa se desenvolve em 3 etapas, a saber: 1) levantamento de artigos na Portal de Periódicos Capes, utilizando a palavra-chave educação de jovens e adultos; 2) análise dos artigos identificados e classificados por temáticas na primeira etapa; 3) seleção, organização e definição dos verbetes para elaboração de um glossário de Educação de Jovens e Adultos.

O estudo sobre o qual se baseia este artigo se situa nas produções desenvolvidas na segunda etapa da pesquisa nacional e contempla o eixo temático: Sujeitos da $\mathrm{EJA}^{2}$. O levantamento realizado permitiu identificar elementos que 


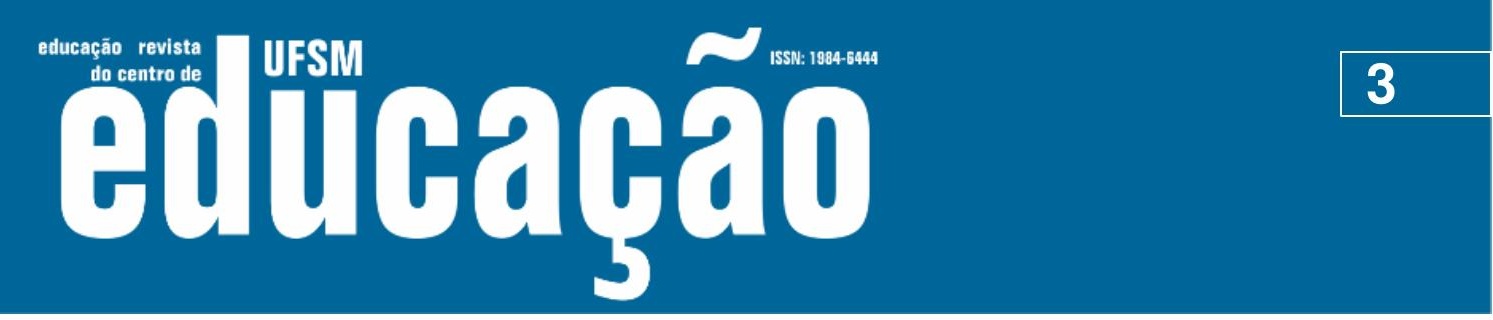

ISSN: 1984-6444 | http://dx.doi.org/10.5902/1984644461367

caracterizam a heterogeneidade das turmas de EJA e demandas relativas a adequações de mediações pedagógicas e currículos que considerem tais especificidades dos sujeitos. Nesse sentido, outras reflexões se desdobraram em novas inquietações: se os currículos e as práticas pedagógicas desenvolvidas na EJA se orientam por percepções sobre os sujeitos, produzem-nas e são revisitados por elas, como os materiais didáticos utilizados nas mediações pedagógicas "dialogam" com as compreensões acerca desses educandos? Os materiais didáticos atendem e/ou "materializam" as especificidades dos estudantes da EJA?

Essas inquietações promoveram aproximações teóricas a trabalhos que tratam sobre os usos, concepções e elaboração de materiais didáticos voltados para essa modalidade de ensino. Esse diálogo entre produções intenta responder à seguinte questão: como as percepções sobre os sujeitos estudantes, influenciam na escolha e/ou na produção dos materiais didáticos utilizados nas mediações pedagógicas na EJA?

Para tal, serão apresentados, inicialmente, os referenciais que fundamentaram o estudo sobre as categorias "sujeitos da EJA" e as mediações pedagógicas na EJA; em seguida, o percurso metodológico que conduziu a pesquisa que subsidia os dados para este trabalho; posteriormente, serão desenvolvidas as análises acerca dos dados coletados na pesquisa sobre os sujeitos e a articulação teórica com as produções que versam sobre os materiais didáticos utilizados nessa modalidade de ensino; por fim, serão tecidas as considerações sobre essa articulação.

Os sujeitos da Educação de Jovens e Adultos e as mediações pedagógicas na EJA

As pesquisas que tomam os sujeitos da EJA como foco de análise nos permitem afirmar que, ao abordarmos essa categoria, podemos fazê-la a partir de diferentes dimensões, considerando: as questões legais, os aspectos cognoscitivos, os elementos geracionais, as situações de classe social, de gênero, de raça/etnia, de origem (urbana ou do campo), os aspectos históricos, socioculturais, econômicos e/ou 


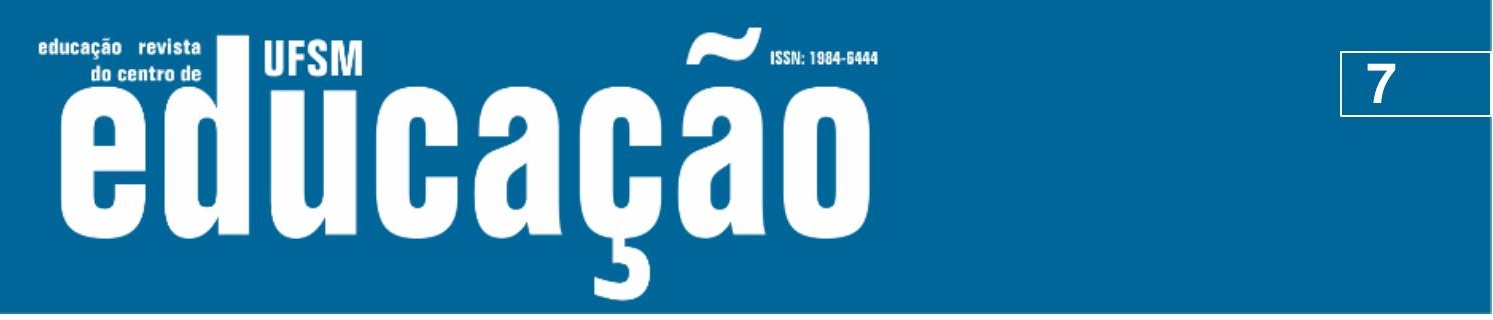

ISSN: 1984-6444 | http://dx.doi.org/10.5902/1984644461367

A função qualificadora, [afirma] o caráter permanente da aprendizagem. [...] Essa função requer ações dos diferentes sujeitos envolvidos no processo, especialmente, no apelo feito às instituições para a produção adequada de materiais didáticos. [...] Materiais que reflitam as realidades e vivências cotidianas de aprendizagem, levando em consideração as especificidades locais no qual esse material será trabalhado. (SARTORI, 2011, p. 74-76)

Essa função se torna importante para analisar as ações pedagógicas desenvolvidas na EJA. Ao considerarmos jovens, adultos e idosos estudantes como sujeitos que inscrevem suas trajetórias de vida em contextos variados, que partilham das experiências socioculturais de um grupo e que vivenciam outros espaços de aprendizagem e de produção de conhecimento, as mediações pedagógicas precisam possibilitar esse espaço de fala e escuta aos sujeitos. De reconhecimento e acolhida dos saberes que eles produzem e elaboram em sua existência fora da escola.

Para Laffin (2008), pensar as mediações pedagógicas na EJA nessa perspectiva, significa considerar algumas questões relevantes ao processo: como entendemos a produção do conhecimento no espaço escolar? Qual é o conhecimento válido e possível nesse espaço? O que significa pensar nos sujeitos da EJA como pessoas capazes de participar ativamente nos processos de ensino e aprendizagem? Como a relação estabelecida entre professor e educando torna possível uma prática dialógica?

A autora, partindo da teoria da atividade, identifica que algumas mediações se tornam possíveis quando: o planejamento de ensino se organiza mediante problemas materiais ou conceituais (em aproximação com a vida e conhecimento dos estudantes); as metodologias e materiais utilizados nas diferentes ações são providos no sentido de auxiliar no processo de elaboração conceitual; as ações transcenderem às experiências e saberes produzidos a partir da experiência imediata com o mundo, garantindo que os alunos se apropriem do conhecimento não-cotidiano, possibilitando a formação do pensamento teórico (conceitual). (LAFFIN, 2008)

Para tal, é necessário tomar a compreensão dos educandos aqui partilhada. Considerando as mais variadas especificidades dos sujeitos da EJA, torna-se relevante apresentar o que as pesquisas nesse campo têm produzido e como contribuem para avançar na compreensão sobre esse público heterogêneo. No 


\section{Tusm

ISSN: 1984-6444 | http://dx.doi.org/10.5902/1984644461367

4. Construção de sínteses prévias, considerando: o tema, os objetivos, as problemáticas, as metodologias, as relações entre o pesquisador e a área, e os resultados;

5. Leitura e análise dos textos na íntegra dos "achados" do corpus encontrado e sua análise de conteúdo;

6. Identificação das abordagens, fundamentos teórico-metodológicos e aprofundamento dos principais autores e bases epistemológicas que referenciam as pesquisas analisadas.

Conforme mencionado, o primeiro levantamento na Portal de Periódicos Capes, localizou 11 produções. A segunda coleta utilizou as palavras-chaves: identidade+EJA; sociabilidade+EJA. Verificou-se mais 02 artigos. As publicações datam de 2006 a 2017.

Para tecer as aproximações teóricas propostas para esse artigo, foi feito um recorte temático. Assim, serão apresentados: 1) as informações gerais necessárias para situar os artigos na produção acadêmica (título, autores, ano de produção; metodologia); 2) as categorias de análise das pesquisas; 3) os principais resultados encontrados.

As percepções sobre os sujeitos em pesquisas na Educação de Jovens e Adultos

Conforme mencionado, identificaram-se 13 trabalhos coletados no Portal de Periódicos Capes que versavam sobre os sujeitos da EJA. Na totalidade de 460 produções identificadas, elas representam apenas $2,41 \%$ dos artigos. O quadro abaixo organiza os textos pelo ano de produção, o título do trabalho e seus autores: 


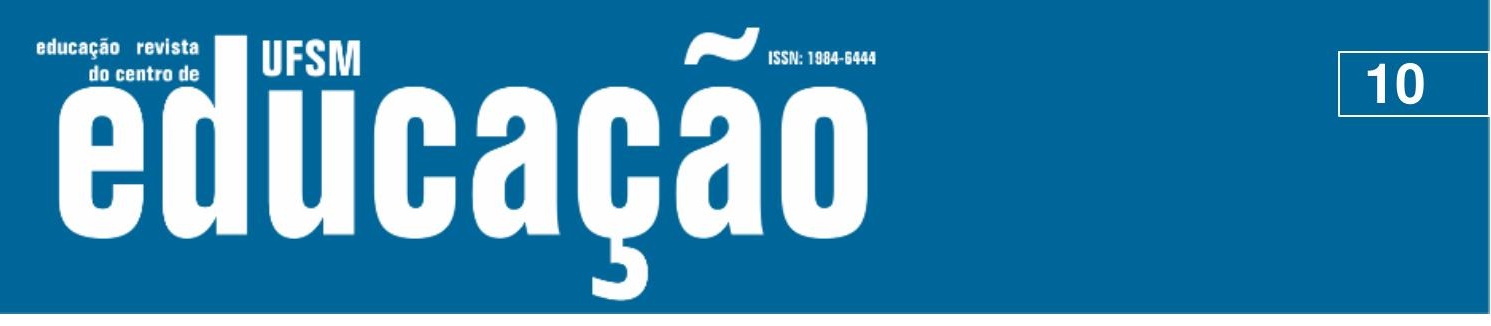

ISSN: 1984-6444 | http://dx.doi.org/10.5902/1984644461367

Quadro 1 - A produções sobre sujeitos da EJA

\begin{tabular}{|c|c|c|}
\hline Ano & Título do artigo & Autores \\
\hline 2006 & $\begin{array}{l}\text { Educação de Juventudes: o lugar da escola nas } \\
\text { representações dos jovens }\end{array}$ & ESTÈVÃO, C. V. \\
\hline 2010 & $\begin{array}{l}\text { Formação de educadores: uma perspectiva de } \\
\text { educação de idosos em programas de EJA }\end{array}$ & $\begin{array}{l}\text { MARQUES, D. T.; PACHANE, G. } \\
\text { G. }\end{array}$ \\
\hline 2010 & $\begin{array}{l}\text { Falar de mim é fácil, difícil é ser Eu: Estratégias } \\
\text { discursivo-interacionais de Construção de Identidades } \\
\text { por Alunos de EJA no Orkut. }\end{array}$ & $\begin{array}{l}\text { ANACLETO, E. A. F.; LADEIRA, } \\
\text { W. T. }\end{array}$ \\
\hline 2011 & $\begin{array}{l}\text { Educação de jovens e adultos: o retorno das mulheres } \\
\text { à escola }\end{array}$ & $\begin{array}{l}\text { RIEGER, M.; ALEXANDRE, I. de } \\
\text { J. }\end{array}$ \\
\hline 2012 & $\begin{array}{l}\text { O discurso curricular intercultural na Educação de } \\
\text { jovens e adultos e a produção de subjetividades }\end{array}$ & $\begin{array}{l}\text { CARVALHO, Rosângela Tenório } \\
\text { de }\end{array}$ \\
\hline 2012 & $\begin{array}{l}\text { Rejuvenescimento da Educação de Jovens e Adultos - } \\
\text { EJA: prática de inclusão ou exclusão? }\end{array}$ & $\begin{array}{l}\text { SOUZA, C. R. S. e; AZAMBUJA, } \\
\text { G. e; PAIXÃO, S. de O. }\end{array}$ \\
\hline 2012 & $\begin{array}{l}\text { A cabeça pensa a partir de onde os pés pisam: os } \\
\text { sujeitos jovens e a EJA }\end{array}$ & FURINI, D. R. M. \\
\hline 2015 & $\begin{array}{l}\text { O ethos discursivo do aluno da Educação de Jovens e } \\
\text { Adultos: uma abordagem acerca da identidade dos } \\
\text { alunos do } 1^{\circ} \text { e } 2^{\circ} \text { segmento da EJA de uma instituição } \\
\text { de ensino da rede municipal de Betim }\end{array}$ & 1. P. A. da. \\
\hline 2015 & $\begin{array}{l}\text { Teorias pós-críticas da juventude: juvenilização, } \\
\text { tribalismo e socialização ativa }\end{array}$ & GROPPO, L. A. \\
\hline 2016 & $\begin{array}{l}\text { Estado de conhecimento da pesquisa acadêmica sobre } \\
\text { o aluno adulto da educação de jovens e adultos (2011- } \\
2014 \text { ) }\end{array}$ & $\begin{array}{l}\text { CONZATTI, } \quad \text { F. de } \quad \text { B. K.; } \\
\text { DAVOGLIO, T. R. }\end{array}$ \\
\hline 2016 & $\begin{array}{l}\text { Estudantes da Educação de Jovens e Adultos: } \\
\text { considerações sobre o perfil e desempenho escolar }\end{array}$ & $\begin{array}{l}\text { FERREIRA, A. A.; MARTINELLI, } \\
\text { S. de C. }\end{array}$ \\
\hline 2017 & $\begin{array}{l}\text { Juventudes, Educação do Campo e Formação Técnica: } \\
\text { um estudo de caso do IFMT }\end{array}$ & $\begin{array}{l}\text { SENRA, R. E. F.; SATO, M. T.; } \\
\text { MELLO, G. J.; CAMPOS, A. G. de. }\end{array}$ \\
\hline 2017 & $\begin{array}{l}\text { Juventudes na EJA: Contradições entre suas } \\
\text { conquistas como sujeito de direito e os silenciamento } \\
\text { nos espaços escolares }\end{array}$ & SOUZA, E. O. S.; REIS, R. \\
\hline
\end{tabular}

Fonte: Elaborado e publicado por Santos e Silva, 2020.

A partir da leitura dos resumos e dos textos completos, foi possível identificar, em alguns artigos, os tipos e as metodologias das pesquisas:

Quadro 2 - Tipo de pesquisa

\begin{tabular}{|c|c|c|c|}
\hline \multicolumn{3}{|c|}{ Pesquisas de abordagem qualitativas } & $\begin{array}{c}\text { Pesquisas de abordagem } \\
\text { quantitativa }\end{array}$ \\
\hline Bibliográfica & Estudo de caso & Não mencionada & $\begin{array}{c}\text { Análise estatísticas descritiva e } \\
\text { comparativa }\end{array}$ \\
\hline 05 & 04 & 03 & 01 \\
\hline
\end{tabular}

Fonte: Elaborado pelos autores a partir da análise dos dados da pesquisa, 2018. 


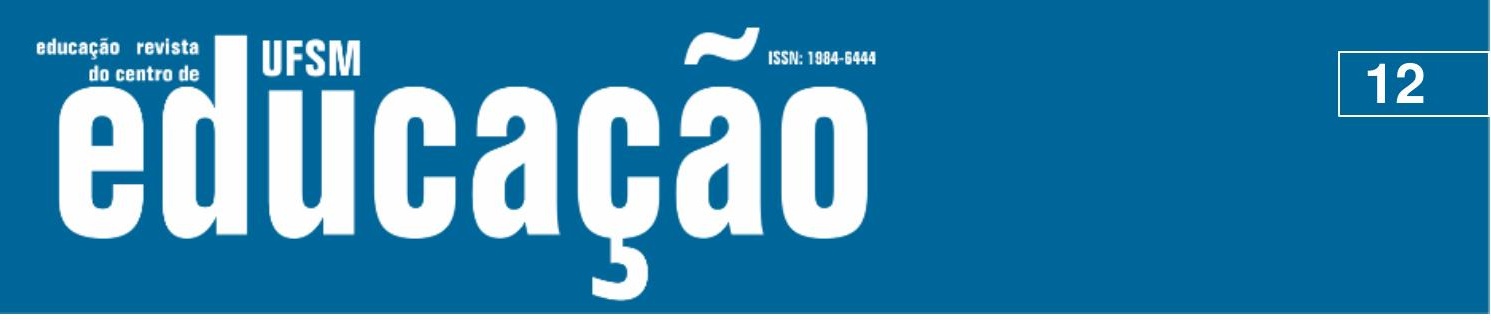

ISSN: 1984-6444 | http://dx.doi.org/10.5902/1984644461367

\section{Continuação Quadro 3 - Objetivos e resultados das pesquisas}

\begin{tabular}{|c|c|c|}
\hline $\begin{array}{l}\text { Estudantes da } \\
\text { Educação de } \\
\text { Jovens e Adultos: } \\
\text { considerações } \\
\text { sobre o perfil e } \\
\text { desempenho } \\
\text { escolar }\end{array}$ & $\begin{array}{l}\text { Investigar o perfil e o desempenho } \\
\text { escolar de jovens e adultos em } \\
\text { processo de alfabetização. }\end{array}$ & $\begin{array}{l}\text { Os resultados apontaram que a maioria } \\
\text { dos estudantes, interromperam os estudos } \\
\text { por motivos de trabalho; retornaram à } \\
\text { escola em busca de realização pessoal; } \\
\text { apresentaram baixo desempenho em } \\
\text { escrita e aritmética e bom desempenho em } \\
\text { leitura. }\end{array}$ \\
\hline $\begin{array}{l}\text { Falar de mim é } \\
\text { fácil, difícil é ser } \\
\text { Eu: Estratégias } \\
\text { discursivo- } \\
\text { interacionais de } \\
\text { Construção de } \\
\text { ldentidades por } \\
\text { Alunos de EJA no } \\
\text { Orkut. }\end{array}$ & $\begin{array}{l}\text { Verificar como os alunos } \\
\text { constroem sua identidade no site } \\
\text { de relacionamentos Orkut, } \\
\text { considerando a linguagem como } \\
\text { prática social. }\end{array}$ & $\begin{array}{l}\text { Considerou de que os indivíduos } \\
\text { constroem suas identidades do modo que } \\
\text { desejam ser enxergados, pelos outros, ou } \\
\text { pensam que serão enxergados e de que } \\
\text { irá moldar a sua identidade pelo olhar do } \\
\text { outro. }\end{array}$ \\
\hline $\begin{array}{lr}\text { Formação } & \text { de } \\
\text { educadores: } & \text { uma } \\
\text { perspectiva } & \text { de } \\
\text { educação de } & \\
\text { idosos } & \text { em } \\
\text { programas de EJA }\end{array}$ & $\begin{array}{l}\text { Discutir sobre a formação docente } \\
\text { para atuação na EJA, } \\
\text { principalmente com estudantes } \\
\text { idosos. }\end{array}$ & $\begin{array}{l}\text { As autoras concluem que é necessário, } \\
\text { para a formação do pedagogo, a inclusão } \\
\text { nos currículos estudos relativos aos alunos } \\
\text { idosos, oriundos das classes populares, e } \\
\text { ao envelhecimento, ampliando as } \\
\text { temáticas do campo da educação. }\end{array}$ \\
\hline $\begin{array}{l}\text { Juventudes na } \\
\text { EJA: Contradições } \\
\text { entre ruas } \\
\text { conquistas como } \\
\text { sujeito de direito e } \\
\text { os silenciamento } \\
\text { nos espaços } \\
\text { escolares }\end{array}$ & $\begin{array}{l}\text { Estabelecer relações entre os } \\
\text { marcos legais dos direitos } \\
\text { humanos no que concerne às } \\
\text { juventudes, contrapondo-se ao } \\
\text { silenciamento dos sujeitos jovens } \\
\text { nessa modalidade de ensino. }\end{array}$ & $\begin{array}{l}\text { Considerou a importância de uma EJA que } \\
\text { articule ações político-sociais, com o } \\
\text { intuito de fomentar no ambiente escolar o } \\
\text { respeito às diferenças, à igualdade de } \\
\text { oportunidades, à cooperação, à } \\
\text { solidariedade e ao enfrentamento a todo o } \\
\text { tipo de violência, preconceito e } \\
\text { discriminação. }\end{array}$ \\
\hline $\begin{array}{l}\text { Juventudes, } \\
\text { Educação } \\
\text { Campo } \\
\text { Formação } \\
\text { Técnica: } \\
\text { estudo de caso do } \\
\text { IFMT }\end{array}$ & $\begin{array}{l}\text { Descrever sobre o processo da } \\
\text { certificação da qualificação } \\
\text { profissional quer envolve } \\
\text { diretamente a } \quad \text { juventude } \\
\text { camponesa. E da } \\
\text { intencionalidade em se trabalhar } \\
\text { com a dimensão da juventude } \\
\text { camponesa. }\end{array}$ & $\begin{array}{l}\text { Evidenciou que os aspectos burocráticos } \\
\text { da governabilidade } \\
\text { impedem o IFMT de cumprir o seu papel } \\
\text { social. Por este fator, também, verificou-se } \\
\text { que este modelo de educação foi muito } \\
\text { além dos aparatos burocráticos, } \\
\text { afirmando-se como Educação do Campo, } \\
\text { emancipatória e transformadora. }\end{array}$ \\
\hline $\begin{array}{lr}0 & \text { discurso } \\
\text { curricular } & \\
\text { intercultural } & \text { na } \\
\text { Educação } & \text { de } \\
\text { jovens e adultos e } \\
\text { a produção } \\
\text { subjetividades }\end{array}$ & $\begin{array}{l}\text { Desenvolver um estudo sobre o } \\
\text { eixo pedagógico e as regras de } \\
\text { normalização da formação } \\
\text { discursiva da interculturalidade no } \\
\text { campo da educação de jovens e } \\
\text { adultos, com vistas a analisar os } \\
\text { enunciados que conformam o } \\
\text { sujeito da interculturalidade. }\end{array}$ & $\begin{array}{l}\text { Em relação à produção de subjetividades } \\
\text { no discurso curricular, pode-se considerar, } \\
\text { a partir de uma perspectiva nietzscheana, } \\
\text { que, ao dizer-se da interculturalidade em } \\
\text { substituição à homogeneização cultural, } \\
\text { diz-se também daquilo que se é. }\end{array}$ \\
\hline
\end{tabular}




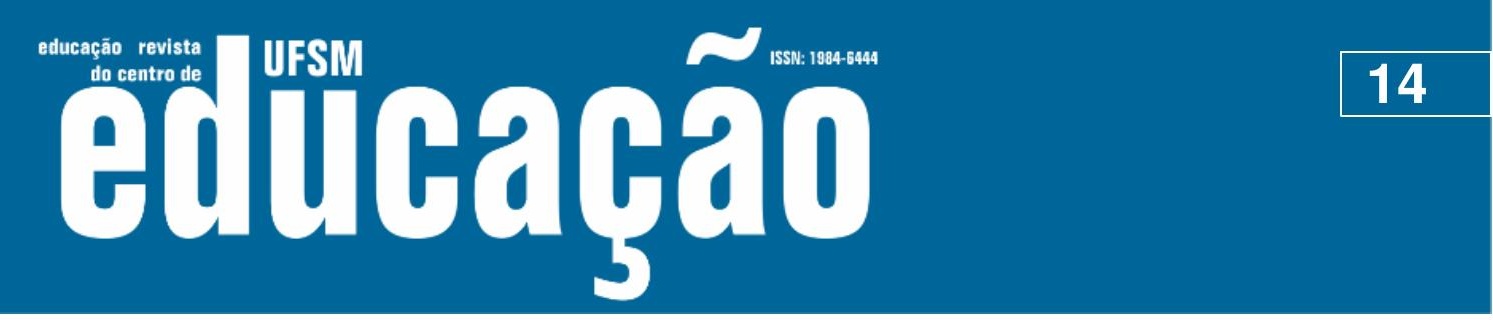

ISSN: 1984-6444 | http://dx.doi.org/10.5902/1984644461367

Os trabalhos também foram analisados a partir de suas categorias de análise e foi possível aproximá-las em grupos temáticos:

Quadro 4 - Grupos temáticos e categorias de análise

\begin{tabular}{|c|c|c|c|}
\hline Grupos temáticos & Categorias & Autores & $\begin{array}{l}\text { Número de } \\
\text { produções }\end{array}$ \\
\hline Sujeitos da EJA e Geração & $\begin{array}{l}\text { Velhice, envelhecimento, } \\
\text { idoso, cidadania, exclusão } \\
\text { social, diversidade, inclusão; } \\
\text { aluno adulto, adulto, } \\
\text { "sujeitos alunos adultos da } \\
\text { EJA" }\end{array}$ & $\begin{array}{lrr}\text { Marques } & \text { e } & \text { Pachane } \\
\text { (2010); } & \text { Conzatti e } \\
\text { Davoglio } & (2016) ; \\
\text { Ferreira } & \text { e } & \text { Martinelli } \\
(2016) ; & & \text { Souza, } \\
\text { Azambuja } & \text { e } & \text { Pavão } \\
(2012) & & \\
\end{array}$ & 04 \\
\hline Sujeitos EJA e Gênero & $\begin{array}{ll}\text { Gênero, } & \text { mulheres, } \\
\text { conscientização/libertação }\end{array}$ & $\begin{array}{lll}\begin{array}{l}\text { Rieger } \\
(2011)\end{array} & \text { e } & \text { Alexandre } \\
\end{array}$ & 01 \\
\hline $\begin{array}{l}\text { Sujeitos EJA, processos de } \\
\text { aprendizagem } \\
\text { desempenho escolar }\end{array}$ & $\begin{array}{l}\text { Alfabetização, EJA e } \\
\text { desempenho escolar }\end{array}$ & $\begin{array}{l}\begin{array}{l}\text { Ferreira e } \\
(2016)\end{array} \\
\end{array}$ & 01 \\
\hline $\begin{array}{l}\text { Formação de educadores } \\
\text { para compreensão das } \\
\text { especificidades dos sujeitos } \\
\text { da EJA }\end{array}$ & $\begin{array}{l}\text { Formação de educadores } \\
\text { para a EJA; EJA; educação; } \\
\text { dialogicidade }\end{array}$ & $\begin{array}{l}\text { Marques e Pachane } \\
(2010)\end{array}$ & 01 \\
\hline $\begin{array}{l}\text { Currículo, discursos e } \\
\text { constituições identitárias dos } \\
\text { sujeitos }\end{array}$ & $\begin{array}{l}\text { Currículo, discurso, poder, } \\
\text { processos de subjetivação, } \\
\text { técnicas de si, } \\
\text { interculturalidade, ethos } \\
\text { discursivo, imaginário socio- } \\
\text { discursivo. }\end{array}$ & $\begin{array}{l}\text { Carvalho (2012); Aniceto } \\
\text { e Ladeira (2010); Silva } \\
\text { (2015) }\end{array}$ & 03 \\
\hline $\begin{array}{l}\text { Dimensões sociológicas da } \\
\text { concepção de Juventude }\end{array}$ & $\begin{array}{l}\text { Juventude, sentido de } \\
\text { escola, representação de } \\
\text { aluno, sujeito, direitos } \\
\text { humanos. }\end{array}$ & $\begin{array}{l}\text { Estèvão (2006); Furini } \\
\text { (2012); Souza e Reis } \\
\text { (2017); Groppo (2015) }\end{array}$ & 04 \\
\hline $\begin{array}{l}\text { Juventudes e Formação } \\
\text { Profissional e Técnica }\end{array}$ & $\begin{array}{l}\text { Juventudes, } \\
\text { social e enalificação } \\
\text { educação do campo }\end{array}$ & $\begin{array}{l}\text { Senra, Sato e Melo } \\
(2017)\end{array}$ & 01 \\
\hline
\end{tabular}

Fonte: Elaborado e publicado por Santos e Silva, 2020.

Os grupos temáticos e as categorias a eles relacionadas permitiram perceber em torno de quais elementos se reúnem as produções que tratam sobre os sujeitos da EJA; quais são as temáticas identificadas pelos pesquisadores como relevantes para compreendê-los e acolhê-los. É importante destacar que os trabalhos não propuseram uma análise sobre os processos de aprendizagem desenvolvidos por esses sujeitos, mas apontam quais são os elementos sociais, históricos e culturais que perpassam o entendimento sobre eles enquanto mobilizadores da aprendizagem. Também é 


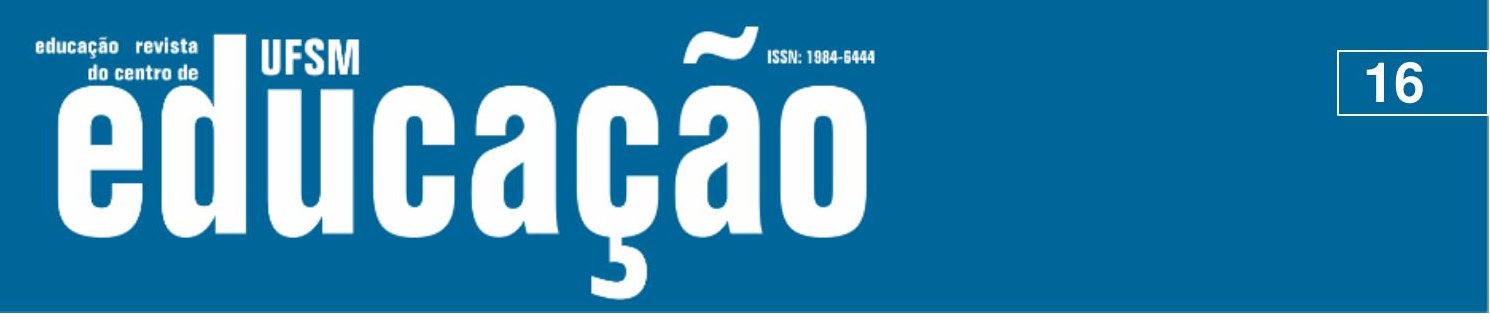

ISSN: 1984-6444 | http://dx.doi.org/10.5902/1984644461367

Os trabalhos que versam sobre o uso de materiais didáticos na EJA foram localizados no Portal de Periódicos Capes a partir das palavras-chaves "material didático+EJA", utilizando-se também o filtro de resultados "Tópico Educação de Jovens e Adultos". Foram encontrados 10 artigos e destes, 09 apontaram temáticas específicas sobre o uso de alguns materiais para o ensino de determinados conteúdos de componentes curriculares:

Quadro 5 - As produções sobre materiais didáticos na EJA

\begin{tabular}{|c|l|l|}
\hline Ano & \multicolumn{1}{|c|}{ Título } & \multicolumn{1}{|c|}{ Autores } \\
\hline 2008 & $\begin{array}{l}\text { Discursos sobre saúde na educação de jovens e adultos: uma } \\
\text { análise crítica da produção de materiais educativos de ciências }\end{array}$ & $\begin{array}{l}\text { VILANOVA, R.; } \\
\text { MARTINS, I. P. }\end{array}$ \\
\hline 2011 & $\begin{array}{l}\text { Expectativas de Jovens e Adultos do Ensino Médio Sobre a } \\
\text { Escola e sua Relação com a Disciplina de Biologia: uma } \\
\text { experiência em uma escola pública do Rio de Janeiro }\end{array}$ & JALOTO, A. M. \\
\hline 2012 & $\begin{array}{l}\text { Professores que lecionam matemática na EJA: concepções e e } \\
\text { práticas letivas }\end{array}$ & $\begin{array}{l}\text { THEES, A.; FANTINATO, } \\
\text { M. C. }\end{array}$ \\
\hline 2013 & $\begin{array}{l}\text { Um novo olhar sobre a produção didática da EJA: as produções } \\
\text { do meio escolar }\end{array}$ & MELLO, P. E. D. de \\
\hline 2013 & Jovens e Adultos Construindo e Interpretando Gráficos & LIMA, l.; SELVA, A. \\
\hline 2014 & $\begin{array}{l}\text { Pesquisas e Documentos Curriculares no Âmbito da Educação } \\
\text { Matemática de Jovens e Adultos }\end{array}$ & $\begin{array}{l}\text { JANUARIO, G.; } \\
\text { FREITAS, A.; LIMA, K. }\end{array}$ \\
\hline 2014 & $\begin{array}{l}\text { Trajetórias do currículo de geografia que se ensina a jovens e } \\
\text { adultos trabalhadores }\end{array}$ & SERRA, E. dos S. \\
\hline 2015 & $\begin{array}{l}\text { O panorama das publicações sobre educação ambiental na } \\
\text { educação de jovens e adultos nos últimos dez anos (2005- } \\
\text { 2014) }\end{array}$ & ALKIMIN, G. \\
\hline 2016 & $\begin{array}{l}\text { Educação de jovens e adultos e novas tecnologias da da } \\
\text { informação: uma abordagem educacional }\end{array}$ & $\begin{array}{l}\text { SILVA, C.; SOUZA, C.; } \\
\text { CARMO, G. }\end{array}$ \\
\hline 2017 & $\begin{array}{l}\text { Uma análise do ensino de geografia em materiais didáticos da } \\
\text { EJA }\end{array}$ & $\begin{array}{l}\text { VICENTE, V. R. R. de; } \\
\text { MOREIRA, J. A. da S. }\end{array}$ \\
\hline
\end{tabular}

Fonte: Elaborado pelos autores a partir de levantamento realizado no Portal Periódicos Capes, 2019.

Nenhuma das produções apontava para um estudo sobre os sujeitos da aprendizagem. O foco estava nos materiais didáticos e suas potencialidades para o ensino. Para tornar as aproximações teóricas possíveis, foi selecionado o artigo de Mello (2013), Um novo olhar sobre a produção didática da EJA: as produções do meio escolar. A escolha se deve ao fato de ele dispor de uma abordagem mais ampla sobre o uso de materiais didáticos na EJA, sem focalizar em um componente curricular específico ou em um tipo de recurso. $O$ trabalho apresentava uma revisão de literatura 


\section{Tusm Eutlatato

ISSN: 1984-6444 | http://dx.doi.org/10.5902/1984644461367

trabalho de supressão era observado nos textos, nas atividades direcionadas aos estudantes e nos exercícios. Além disso, algumas modificações não passaram pelo crivo dos autores, dando a entender que tenham sido organizadas pelas equipes editoriais.

Assim, ela concluiu que os livros comercializados para a EJA e que constavam nos catálogos do Programa Nacional do Livro Didático, não foram elaborados a partir de um entendimento sobre como os sujeitos da EJA aprendem ou do que seja relevante às suas experiências escolares e de vida. A adaptação desses materiais pode ser entendida a partir de uma concepção de educação destinada a jovens e adultos baseada na ideia de suplência e os sujeitos da EJA, como aqueles que "correm atrás do tempo perdido". Justificando-se, assim, o material resumido, "recortado" de livros didáticos destinados a outros níveis de ensino da educação básica.

A análise de tais pesquisas permitiu compreender que aqueles materiais didáticos elaborados a partir da compreensão dos sujeitos da aprendizagem e das realidades vivenciadas na EJA - o que vem a caracterizar suas especificidades apresentavam-se como mais significativos para serem utilizados como ferramentas de aproximação aos conhecimentos escolares produzidos na educação de jovens e adultos. Os usos e apropriações deles por professores e educandos se fazia de forma mais satisfatória e atendiam às demandas educativas percebidas pelos docentes em sala de aula.

\section{Considerações finais}

Este artigo buscou articular as compreensões sobre os sujeitos da EJA e o uso de materiais didáticos nas mediações pedagógicas realizadas nessa modalidade de ensino, a partir de dois processos de investigação e de análise: o primeiro resultado de uma pesquisa bibliográfica do tipo estado do conhecimento e o segundo, reflexo desta, uma aproximação teórica com trabalhos que analisavam materiais didáticos utilizados na EJA. 


\section{Aillbapẫ

ISSN: 1984-6444 | http://dx.doi.org/10.5902/1984644461367

Sintetizando os dados apresentados anteriormente, seria possível destacar a maneira como os sujeitos da EJA têm sido abordados nas produções resultantes de pesquisa: 1) como sujeitos socioculturais que partilham de um momento de vida e de um tempo histórico (geração); 2) enquanto sujeitos socioculturais, são atravessados pelos diversos recortes que em momentos favorecem ou dificultam seu envolvimento com o processo de escolarização e aprendizagem, a saber: gênero; raça/etnia; origem de moradia; de classe social; 3) pensados por esses elementos, não são tomados apenas pela dimensão cognitiva, mas também, pelas dimensões socioculturais (como sugere Oliveira, 1999);

Em aproximação com as pesquisas sobre os materiais didáticos destinados à EJA, foi possível observar ao menos dois movimentos: um primeiro que evidencia a necessidade e importância de conceber os materiais didáticos a partir dessas compreensões sobre os sujeitos educandos; e, um segundo, que identifica nos livros didáticos comerciais destinados ao público da EJA, um distanciamento desses sujeitos e das especificidades que suas trajetórias de vida e escolares imprimem a essa modalidade de ensino - justificando uma apropriação secundária desse material didático por professores e alunos.

Nesse sentido, cabe destacar que se os materiais didáticos são ferramentas utilizadas pelos professores e estudantes para realizar a mediação nos processos de ensino e aprendizagem, as concepções presentes sobre os sujeitos podem influenciar os usos e as apropriações dessas ferramentas em sala de aula. Sendo assim, o entendimento que se tem sobre os sujeitos com os quais se trabalha na educação de jovens e adultos, a compreensão de como os jovens e adultos aprendem e das mediações pedagógicas necessárias para consolidar aprendizagens significativas, incide também na escolha dos materiais e na elaboração de recursos adequados. 


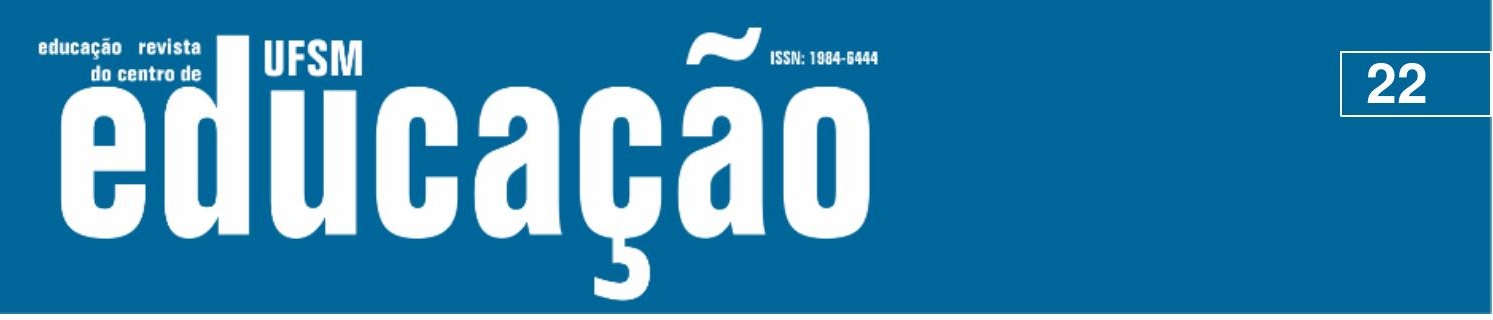

ISSN: 1984-6444 | http://dx.doi.org/10.5902/1984644461367

FERREIRA, Andresa Aparecida; MARTINELLI, Selma de Cássia. Estudantes da Educação de Jovens e Adultos: considerações sobre o perfil e desempenho escolar. Educação: Teoria e Prática, Vol.26 (52), p.312-331, 2016. Disponível em: http://www.periodicos.rc.biblioteca.unesp.br/index.php/educacao/article/view/9233/76 70. Acesso em: 07 abr. 2020

FURINI, Dóris Regina Marroni. A cabeça pensa a partir de onde os pés pisam: os sujeitos jovens e a EJA. Pedagógica: Revista do programa de Pós-graduaçao em Educaçao - PPGE, Vol.14 (29), pp.443-476, 2012. Disponível em: https://bell.unochapeco.edu.br/revistas/index.php/pedagogica/article/view/1459/820 Acesso em: 07 abr. 2020.

GADOTTI, Moacir; ROMÃO, José Eustáquio. Educação de jovens e adultos: teoria, prática e proposta. 5 ed. Cortez: São Paulo. Instituto Paulo Freire, 2002.

GROPPO, Luis Antonio. Teorias pós-críticas da juventude: juvenilização, tribalismo e socialização ativa. Revista Latinoamericana de Ciencias Sociales, Ninez y Juventud, Vol.13(2), p.567(13), 2015. Disponível em: http://www.scielo.org.co/pdf/rlcs/v13n2/v13n2a02.pdf. Acesso em: 07 abr. 2020.

HADDAD, Sérgio (Coord.). O Estado da Arte das Pesquisas em Educação de Jovens e Adultos no Brasil: a produção discente da pós-graduação em educação no período de 1986- 1998. São Paulo: Ação Educativa, 2000. Disponível em: www.bibliotecadigital.abong.org.br/bitstream/handle/11465/1779/40.pdf?sequence $=1$ \&isAllowed=yAcesso em: 07 abr. 2020.

LAFFIN, Maria Hermínia Lage Fernandes. O conhecimento escolar, suas mediações e as atividades de ensinar e aprender. In: LAFFIN, Maria Hermínia Lage Fernandes. (Org.). Crianças, jovens e adultos: diferentes processos e mediações escolares. Florianópolis: Letras Contemporâneas, 2008.

MARQUES, Denise Travassos.; PACHANE, Graziela Giusti. Formação de educadores: uma perspectiva de educação de idosos em programas de EJA. Educação e Pesquisa: Revista da Faculdade de Educação da Universidade de São Paulo, Vol.36(2), pp.475-490, 2010. Disponível em: http://www.revistas.usp.br/ep/article/view/28243/30077. Acesso em: 07 abr. 2020.

MELLO, Paulo Eduardo Dias de. Um novo olhar sobre a produção didática da EJA: as produções do meio escolar. Revista Brasileira de Educação de Jovens e Adultos, Vol. $1, \quad n^{\circ} \quad 1, \quad 2013 . \quad 2$ Disponível https://www.revistas.uneb.br/index.php/educajovenseadultos/article/view/246. Acesso em: 24 mar. 2020.

OLIVEIRA, Marta Kohl de. Jovens e adultos como sujeitos de conhecimento e aprendizagem. Revista Brasileira de Educação. N.12, Set/Out/Nov/Dez, p. 59-73, 1999. 


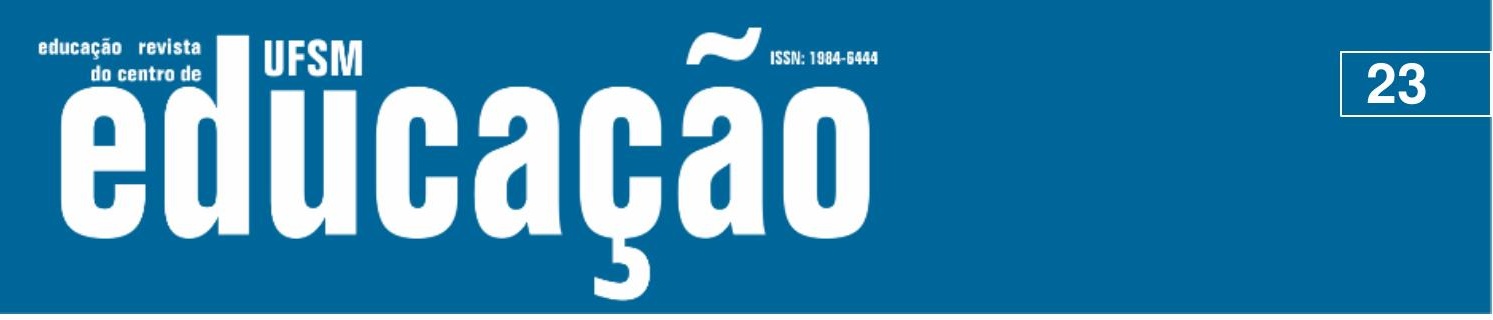

ISSN: 1984-6444 | http://dx.doi.org/10.5902/1984644461367

RIEGER, Marlise; ALEXANDRE, Ivone de Jesus. Educação de jovens e adultos: o retorno das mulheres à escola. Eventos Pedagógicos, 01 December 2011, Vol.2(2). Disponível em: http://sinop.unemat.br/projetos/revista/index.php/eventos/article/view/412/242. Acesso em: 07 abr. 2020.

SANTOS, Pollyana dos; SILVA, Gabriela da. Os Sujeitos da EJA nas Pesquisas em Educação de Jovens e Adultos. Educação e Realidade. v. 45, n. 2, Porto Alegre, 2020. Disponível em http://www.scielo.br/scielo.php?script=sci_arttext\&pid=S2175$62362020000200604 \&$ lng=pt\&nrm=iso. Acesso em: 25 jan. 2021

SARTORI, Anderson. Legislação, políticas públicas e concepções de educação de jovens e adultos. In: LAFFIN, Maria Hermínia Lage Fernandes. (Org.). Educação de jovens e adultos na Diversidade. Florianópolis: Universidade Federal de Santa Catarina, 2011. p. 12-125.

SENRA, Ronaldo Eustáquio Feitoza; SATO, Michèle Tomoko; MELLO, Geison Jader; CAMPOS, Arnaldo Gonçalves de. Juventudes, Educação do Campo e Formação Técnica: um estudo de caso do IFMT. Educação e Realidade, Vol.42 (2), p.605-627, Porto Alegre, 2017. Disponível em: http://www.seer.ufrgs.br/index.php/educacaoerealidade/article/view/55385. Acesso em: 07 abr. 2018.

SILVA, Janine Marta Pereira Antunes da. O ethos discursivo do aluno da Educação de Jovens e Adultos: uma abordagem acerca da identidade dos alunos do $1^{\circ}$ e $2^{\circ}$ segmento da EJA de uma instituição de ensino da rede municipal de Betim. Revista Memento, V.6, n.2, jul.-dez. 2015. Disponível em: http://periodicos.unincor.br/index.php/memento/article/view/2685/pdf_71. Acesso em: 07 abr. 2018.

SOUZA, Carmen Rosane Segatto e Souza; AZAMBUJA, Guacira de; PAIXÃO, Sílvia de Oliveira. Rejuvenescimento da Educação de Jovens e Adultos - EJA: prática de inclusão ou exclusão? Revista Iberoamericana de Educación, Vol. 59, №. Extra 2, 2012. Disponível em: https://dialnet.unirioja.es/servlet/articulo?codigo $=4051789$. Acesso em: 07 abr. 2018.

SOUZA, Emanuelle de Oliveira; REIS, Rosemeire. Juventudes na EJA: contradições entre suas conquistas como sujeito de direito e os silenciamentos nos espaços escolares. HOLOS, Ano 33, Vol. 03, 2017. Disponível em: http://www2.ifrn.edu.br/ojs/index.php/HOLOS/article/view/5747. Acesso em: 07 abr. 2020.

TAKEUCHI, Márcia Regina. Análise Material de Livros Didáticos para Educação de Jovens e Adultos. Dissertação (Mestrado), PUC São Paulo, São Paulo, 2005. 


\section{N-1.

ISSN: 1984-6444 | http://dx.doi.org/10.5902/1984644461367

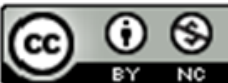

\section{This work is licensed under a Creative Commons Attribution-NonCommercial 4.0 International (CC BY-NC 4.0)}

\section{Notas}

\footnotetext{
${ }^{1}$ A pesquisa é coordenada pela professora Maria Hermínia Lage Fernandes Laffin no contexto do Grupo de Esutos e Pesquisa em Educação de Jovens e Adultos (Epeja) da Universidade Federal de Santa Catarina (Ufsc) . Conta ainda, com colaboradores de diferentes instituições de ensino superior, mobilizando grupos de pesquisa e pesquisadores das cinco regiões país. A equipe da pesquisa também conta com a participação de pesquisadores portugueses vinculados à Universidade de Coimbra e à Universidade do Minho .

${ }^{2}$ Parte dos resultados da pesquisa sobre os Sujeitos da EJA encontram-se publicados em: Santos e Silva, 2020 e sustentam teoricamente este artigo ao abordarmos essa dimensão da pesquisa.

${ }^{3}$ Embora não seja esse o foco das articulações teóricas propostas neste artigo, faz-se importante demarcar que as representações acerca dos sujeitos também são construídas e consolidadas nos processos históricos da educação brasileira e do campo de produção teórica sobre essa área. Nesse sentido, entende-se as ações que o Estado brasileiro assumiu ao longo da história da educação (delegando aos adultos e jovens não alfabetizados o lugar de atendimento por meio de políticas compensatórias, ações escolares de caráter supletivo e aligeiradas) também contribuíram para que representações sobre os sujeitos da EJA fossem consolidadas no imaginário social. Na contramão dessas propostas, o campo de produção de saberes sobre a EJA, estruturou formas de aproximação, organização e desenvolvimento de ações pedagógicas que se fundamentaram em uma visão do educando da EJA como um sujeito sociocultural, inscrito em contextos históricos, ativo e capaz de produzir saberes válidos ao espaço de educação formal. (GADOTTI, 2002; SARTORI, 2011)

4 Informações extraídas parcial ou totalmente do Manual de Orientações para a Realização da Pesquisa: Fundamentos e autores recorrentes do campo da Educação de Jovens e Adultos no Brasil: a construção de um glossário eletrônico, elaborado pela equipe de pesquisadores do Grupo de Estudos e Pesquisas em Educação de Jovens e Adultos (Epeja) da Ufsc, p.07.
} 